\title{
O PROJETO APOLÔNIA
}

De $8 / 7$ a $2 / 8$ de 1998 , realizou-se a $12^{a}$ escavação no sítio de Apolônia-Asurf, Israel, com a participação de uma equipe brasileira formada por professores e alunos de arqueologia. A escavação foi uma etapa do Projeto Apolônia, que é o resultado de um convênio de cooperação científica entre a Universidade de Tel-Aviv (TAU) e a Universidade Federal do Rio Grande do Sul (UFRGS), e que contou com a participação da PUC-RS e do MAE-USP. O objetivo de tal projeto é o de favorecer campos de pesquisa na área de arqueologia clássica mediterrânea.

Desde novembro de 1996, a equipe do Rio Grande do Sul realizou um recenseamento bibliográfico com a preparação e realização de seminários. O Museu de Arqueologia e Etnologia da USP passou a intregar o projeto através de um curso de extensão cultural sobre arqueologia do Mediterrâneo Antigo, ministrado pela Profa. Maria Beatriz B. Florenzano, em maio de 1998, na PUC-RS.

$\mathrm{O}$ sítio de Apolônia-Asurf distingue-se por sucessivas ocupações: persa ( século VI a.C.), helenística, romana (séculos II e III d.C.), bizantina (até 614), árabe, cruzada (a partir de 1100) e turcootomana (a partir de 1265). Está localizado sobre uma colina de arenito, a cerca de 30 metros acima do nível do mar, à margem de um pequeno porto natural do Mediterrâneo. Atualmente, encontra-se dentro da municipalidade de Herzliya a $15 \mathrm{~km}$ ao norte de Tel-Aviv e a $34 \mathrm{~km}$ ao sul de Cesaréia. Foi inicialmente uma cidade cananéia denominada Reshef (deus do fogo, fertilidade e inferno). No terceiro século d.C., o seu nome foi substituído por Apolônia (Apolo). Em 614, foi dominada pelos persas e conquistada pelos árabes, passando a se chamar Asurf. Com a presença dos cruzados a partir de 1100, o seu nome foi trocado por Arsur. Há outras designações históricas para o sítio, tais como: Tel Reshef, Rishpon e Tel Arshaf. Apolônia é escavada desde a década de 50 pelo Instituto de Arqueologia da Universidade de Tel-Aviv em nome da Autoridade de Antiguidades de Israel com o apoio da municipalidade de Herzliya. Desde 1982, as escavações estão sob a coordenação do professor Israel Roll.

Nesta campanha, foi escavada a Área E (lado sul das muralhas da cidade). $O$ método utilizado baseia-se no quadriculamento Wheeler e no método Albright de escavação por locus. A escavação dividiu-se em duas: parte da equipe concentrou-se nas salas romanas já evidenciadas na escavação anterior (1996) e o outro grupo abriu novas quadras com o objetivo de evidenciar a continuação das salas. A primeira parte do dia era dedicada à escavação e à tarde era realizada a seleção dos fragmentos cerâmicos e a lavagem e numeração das peças. Os registros eram feitos em campo por dia e quadra, anotando-se os diferentes materias encontrados: cerâmica, conchas, vidro, ossos, metais e os achados especiais (moedas, jóias, lamparinas e estatuetas). Além da ficha técnica, o registro compunhase também de desenhos das quadras, acompanhando as suas alterações, e de anotações no diário de campo. Sob a orientação do Dr. Roll, uma vez por semana, o grupo se reunia para que fossem explicados o contexto da escavação e as mudanças ocorridas neste período.

A continuidade do projeto inclui a doação de $50 \%$ do material escavado para a UFRGS, no intuito de se constituir um acervo, realizar análises laboratoriais, relatórios e publicações conjuntas, um simpósio no final de 1999, bem como escavações no ano 2000 , contando novamente com a participação brasileira, visando aprofundar a cooperação científica entre as universidades brasileiras e a TAU.

Como um resultado inicial, realizou-se em 9/10, no MAE, a palestra "O Projeto Apolônia", ministrada por Ivana L. Texeira, Juliana C. Monzani e Raquel Rech, a respeito da experiência em Israel e da monografia de mestrado de Raquel Rech a ser defendida no primeiro semestre de 1999.

Participantes: Prof. Dr. Israel Roll (TAU), Prof. Dr. Francisco Marshall (UFRGS), Prof. Dr. Arno Kern (PUC-RS), Prof. Dr. Carlos Roberto Galvão Sobrinho (UNICAMP), Raquel Rech (UFRGS), Ivana L. Texeira, Juliana C. Monzani (MAE-USP), Artur Barcelos (PUC-RS), Claudio Heinrichs Jr., Edison B. Cruxen, Fernanada Ott, João D. M. Saldanha, Mariana P. Cabral, Marieta M. Low, Paulo A. Carneiro, Rodrigo C. Angrizani, Tibério V. Xavier (UFRGS) Mônica Selvatici (UFRJ). 


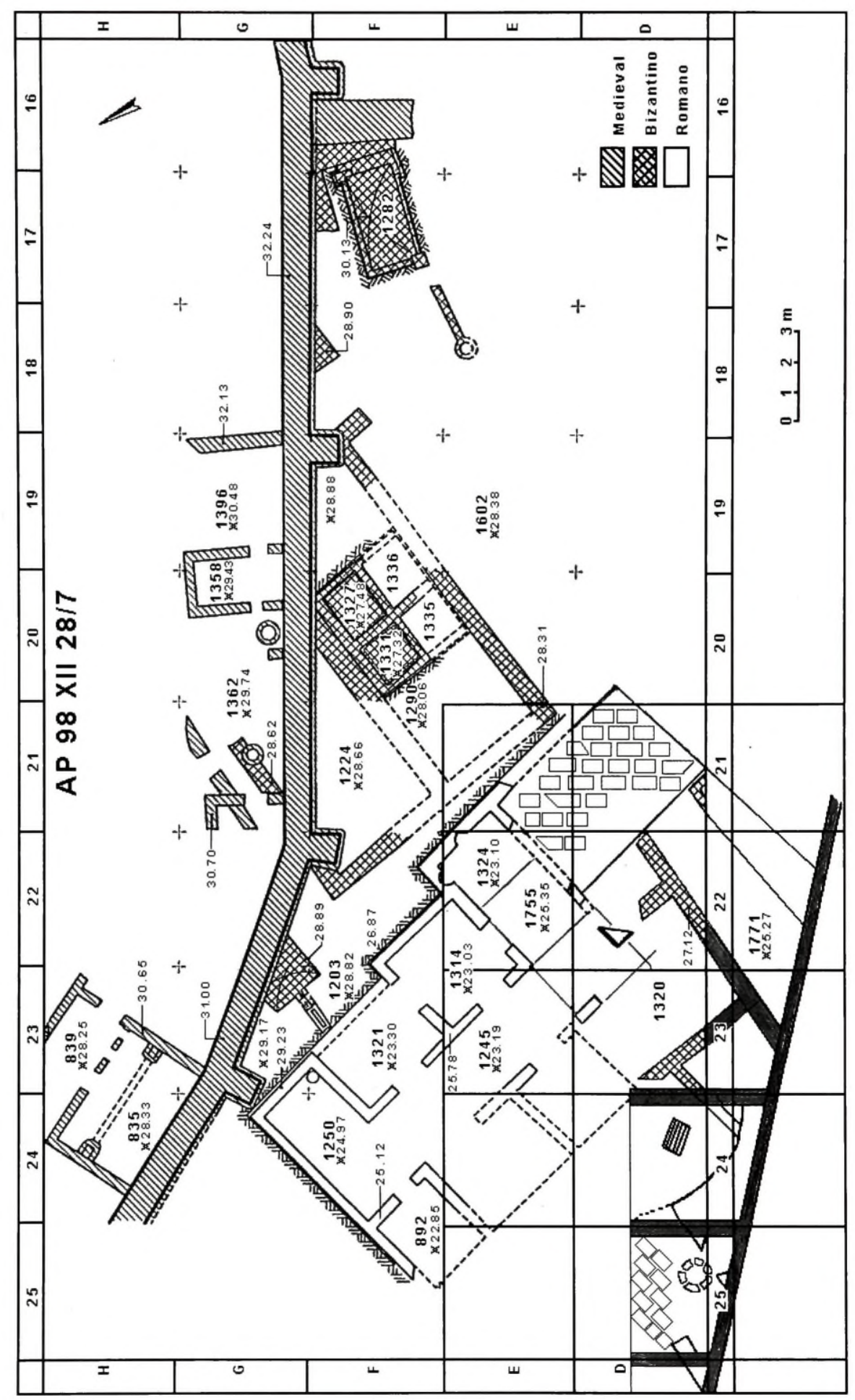




\section{Bibliografia}

ALBRIGHT, W. F.

1949 The Archaeology of Palestine, Londres, Penguim Books.

\section{GROSSMAN, E.}

1997 Maritine Apollonia (Arsuf) and its Harbours. The Mariner's Mirror.

1993 The bronze figurine of the goddess Minerva from Apollonia, Israel. Tel Aviv, 20.

MOSCHE, F.; OREN T.

1996 Two ceramics assemblages from Hellenistic Apollonia. Tel Aviv, 23.

ROLL, I.

1997 Apollonia-Arsuf. Tel-Aviv.

1996 Medieval Apollonia-Arsuf: a fortified costal town in the Levant of the Early Muslim and Crusader periods. Paris.

Recebido para publicação em 20 de novembro de 1998.
1992 Apollonia. The Anchor Bible Dictionaryl. USA.

OREN, T.

1995 Roman-Byzantine cemiteries and tombs around Apollonia. Tel Aviv, 22.

WEXLER, L.; GILBOA, G.

1996 Oil lamps of the Roman period from ApolloniaArsuf. Tel Aviv, 23.

\section{WHEELER, $M$.}

1961 Arqueología de campo. México, Fondo de Cultura Económica.

Ivana Lopes Texeira* Juliana Caldeira Monzani* 